Nilo H. M. Fortes and Jorge A. W. Gut*

\title{
Correction of residence time distribution measurements for short holding times in pasteurization processes
}

https://doi.org/10.1515/ijfe-2020-0109

Received May 13, 2020; accepted September 5, 2020;

published online September 21, 2020

Abstract: When in-line cells are used for obtaining residence time distribution (RTD) data from systems with short residence time, the signal distortion caused by the cell can compromise the results. A procedure to correct such distortion using convolution of signals in the time domain is proposed. First, the RTD of the cell is characterized, and then the E-curve of an RTD model is convoluted with the cell curve. The convoluted E-curve is fitted to the experimental data by adjusting the mean time and the model parameter. The procedure is demonstrated using a pilot scale pasteurization unit with two heaters, one cooler and six options of holding tube. Pulse experiments were performed, E-curves were obtained for each process step and five RTD models were tested. The convolution procedure was successful in removing the distortion caused by the detection cell, which was very significant for the holding tubes.

Keywords: convolution; flow; heat exchanger; pasteurization; RTD.

\section{Nomenclature}

\author{
$C(t) \quad$ exit concentration of tracer $\left(\mathrm{kg} \mathrm{m}^{-3}\right)$ \\ $C_{0} \quad$ background concentration of tracer $\left(\mathrm{kg} \mathrm{m}^{-3}\right)$ \\ $d_{i} \quad$ internal diameter of tube $(\mathrm{m})$ \\ $D_{a x} \quad$ axial dispersion coefficient $\left(\mathrm{m}^{2} \mathrm{~s}^{-1}\right)$ \\ De Dean number (-) \\ $E(t) \quad$ exit age distribution function $\left(\mathrm{s}^{-1}\right)$
}

$\begin{array}{ll}E_{\text {cell }} & \text { exit age distribution function of detection cell }\left(\mathrm{s}^{-1}\right) \\ E_{\theta}(\theta) & \text { dimensionless exit age distribution function }(-) \\ L & \text { tube length }(\mathrm{m}) \\ n & \text { generalized convection model parameter }(-) \\ N & \text { number of tanks in series }(-) \\ P e & \text { Peclet number }(-) \\ Q & \text { volumetric flow rate }\left(\mathrm{m}^{3} \mathrm{~s}^{-1}\right) \\ r & \text { radial dimension }(\mathrm{m}) \\ R & \text { internal radius of the tube }(\mathrm{m}) \\ R^{2} & \text { coefficient of determination }(-) \\ R_{C} & \text { curvature radius of bend }(\mathrm{m}) \\ R e & \text { Reynolds number }(-) \\ \mathrm{SSE} & \text { sum of squared errors on } E(t)\left(\mathrm{s}^{-2}\right) \\ t, t^{\prime} & \text { time (s) } \\ t_{0} & \text { breakthrough time }(\mathrm{s}) \\ t_{m} & \text { mean residence time }(\mathrm{s}) \\ t_{\max } & \text { maximum residence time }(\mathrm{s}) \\ t_{\min } & \text { minimum residence time }(\mathrm{s}) \\ T & \text { average temperature of fluid }\left({ }^{\circ} \mathrm{C}\right) \\ V_{b} & \text { average fluid velocity }\left(\mathrm{m} \mathrm{s}^{-1}\right) \\ V & \text { fluid velocity in the tube }\left(\mathrm{m} \mathrm{s}^{-1}\right) \\ V_{\max } & \text { maximum velocity in the tube }\left(\mathrm{m} \mathrm{s}^{-1}\right) \\ V & \text { system internal volume }\left(\mathrm{m}^{3}\right) \\ V_{A} & \text { active internal volume }\left(\mathrm{m}^{3}\right) \\ V_{m} & \text { mixed flow volume }\left(\mathrm{m}^{3}\right) \\ V_{p} & \text { plug flow volume }\left(\mathrm{m}^{3}\right) \\ y & y \text {-laminar model parameter }(-)\end{array}$

\section{Greek letters}

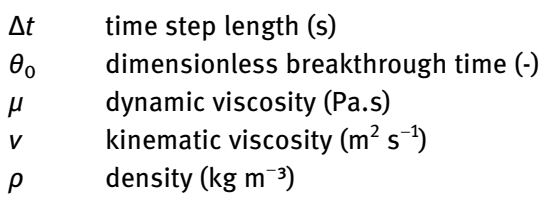

\footnotetext{
*Corresponding author: Jorge A. W. Gut, Department of Chemical Engineering, Escola Politécnica, University of São Paulo, São Paulo, SP, 05588-000, Brazil; and FoRC - Food Research Center, University of São Paulo, SP, 05508-080, Brazil, E-mail: jorgewgut@usp.br. https:// orcid.org/0000-0001-6447-8490

Nilo H. M. Fortes, Department of Chemical Engineering, Escola Politécnica, University of São Paulo, São Paulo, SP, 05588-000, Brazil. https://orcid.org/0000-0003-1763-8329

\section{Subscripts}

$\begin{array}{ll}i & \text { discrete instant of time } i(-) \\ j & \text { discrete instant of time } j(-) \\ \text { in } & \text { inlet } \\ \text { out } & \text { outlet }\end{array}$
}




\section{Introduction}

Continuous pasteurization of liquid foods is a common process in the food industry and is designed for the inactivation of pathogens and also microorganisms and enzymes that reduce the product shelf life. In such processes, plate heat exchangers are commonly used for heating and cooling, while a holding tube ensures the desired holding time at the process temperature. When processing liquid foods with high viscosities or with particulate matter, tubular heat exchangers are more appropriate than plate heat exchangers due to pressure drop limitations $[1,2]$.

The effect of the time and temperature in the inactivation of microorganisms and enzymes can be evaluated through the lethality function for first order kinetics. For process design, only the target inactivation that occurs in the holding tube at the minimum residence time is considered. However, the heating and cooling sections do have some contribution to the lethality when heat transfer is slow, as well as the velocity profile in the holding tube. This can result in undesired degradation of nutrients and bioactive compounds by over processing [3, 4].

The study of the residence time distribution (RTD) is important for the characterization of flow in continuous pasteurization units to evaluate the level of dispersion and the flow pattern. The distribution of fluid elements flowing through a system is represented by the E-curve, which can be obtained through pulse experiments using a tracer. The exit age distribution curve $E(t)$ of a process is calculated from Eq. (1), where $C_{0}$ is the work fluid background concentration, if existent. The area under the curve is unitary, as shown in Eq. (2) [5, 6].

$$
\begin{gathered}
E(t)=\frac{C(t)-C_{0}}{\int_{0}^{\infty} C(t)-C_{0} \mathrm{~d} t} \\
\int_{0}^{\infty} E(t) \mathrm{d} t=1
\end{gathered}
$$

The experimental mean residence time $\left(t_{m}\right)$ can be obtained from Eq. (3), and it can be associated with the system active volume, which does not include stagnating zones or dead volumes $[5,6]$.

$$
t_{m}=\int_{0}^{\infty} t E(t) \mathrm{d} t
$$

The dimensionless time $\theta$ can be defined in terms of the mean residence time, as shown in Eq. (4), and is useful for comparative purposes. With Eq. (5), it is possible to obtain the dimensionless residence time distribution $E_{\theta}(\theta)[5,6]$.

$$
\begin{gathered}
\theta=\frac{t}{t_{m}} \\
E_{\theta}(\theta)=t_{m} \quad E(t)
\end{gathered}
$$

In-line cells can be used to register the tracer concentration at the system's outlet, using an appropriate sampling rate. However, experimental errors can occur if the residence time of the detection cell is close to the system's mean residence time. In this case, the E-curve of the system is distorted by the flow through the cell [7, 8]. Such distortion can be characterized through the convolution integral in Eq. (6). If $C_{\text {in }}$ is the tracer concentration entering the cell, the outlet concentration over time $C_{\text {out }}$ can be obtained if the $E(t)$ function of the cell is known [5].

$$
C_{\text {out }}(t)=\int_{0}^{t} C_{\text {in }}\left(t-t^{\prime}\right) E\left(t^{\prime}\right) \mathrm{d} t^{\prime}
$$

Figure 1 shows an example of non-ideal tracer detection where the E-curve of the system is distorted by the flow in the detection cell. The RTD obtained with the detection cell can be considered as the convolution of the E-curve of the system with the E-curve of the cell $[5,8]$. A way to filter such distortion is discussed in this work considering pasteurization processes.

For the thermal processing of liquid foods, helically coiled tubes are often used in the heat exchangers and holding tube. Studies have confirmed that the use of helical tubes in laminar flow reduces the axial dispersion and the spread of the residence time due to the presence of a secondary flow, in comparison with straight tubes under the same conditions [9-11]. When secondary flow is present, the transition from laminar to turbulent flow occurs at higher Reynolds numbers and Dean number becomes relevant to the study [12]. Also, the higher the number of bends, the narrower the E-curve becomes [13].

A number of researchers have studied flow patterns and their effects on thermal processing of liquid foods. RTD is a useful resource for detecting flow anomalies, such as stagnant zones and bypassing [14]. Studies on the RTD of the heating section of a thermal process were conducted for different systems, such as plate heat exchangers [4], scraped surface heat exchangers [15], tubular heat exchangers $[16,17]$ and even coaxial heat exchanger used for micro reaction systems [18]. Rennie and Raghavan [19] developed a numerical study for a double-pipe helical heat exchanger to determine the residence time, temperature and lethality distributions. Studies have also been carried on the RTD of short holding tubes [8], of high-pressure food process [20], of systems with particulate fluids [21, 22] and of a microwave-assisted pasteurization system [23]. 


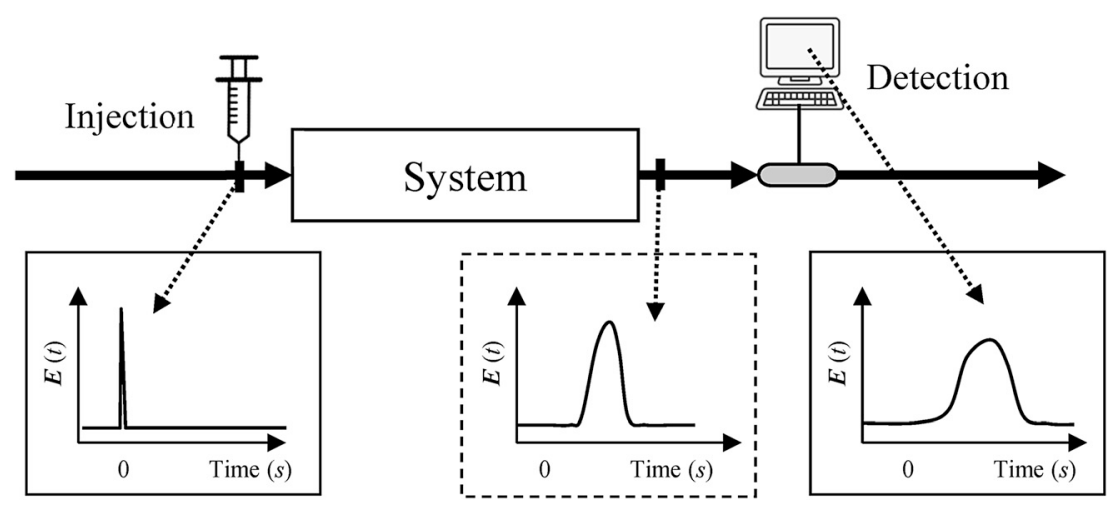

Figure 1: Effect of non-ideal tracer detection and the measured E-curve of the system, adapted from Gutierrez et al. (2010).
To the authors knowledge, few studies have used a convolution procedure in the time domain to study the RTD of systems, including the correction of distortions caused by in-line detection systems $[8,24]$. While the most common procedure is the deconvolution method in frequency domain [25-27], Serres et al. [28] verified that this procedure is very sensitive to noises which lead to a poor RTD characterization.

This work aims to present a procedure to remove distortions in measured RTD data of holding tubes and other process steps caused by non-ideal tracer detection, using convolution in the time domain. This will be illustrated through the study of the RTD of a continuous flow pilot unit used for microwave-assisted pasteurization of low viscosity liquid foods.

\section{Material and methods}

\subsection{Pasteurization unit}

The RTD of a continuous flow microwave-assisted pasteurization unit Lab25-UHT/HTST EHVH (MicroThermics, Raleigh, USA) was characterized through tracer pulse experiments. The unit has a nominal capacity of $0.5 \mathrm{~L} / \mathrm{min}$, a maximum flowrate of $3.0 \mathrm{~L} / \mathrm{min}$ and a maximum processing temperature of $150^{\circ} \mathrm{C}$. The internal diameter of the product line (stainless steel tubing) is $7.75 \mathrm{~mm}$ or $9.40 \mathrm{~mm}$ (nominal $3 / 8$ ” or $1 / 2$ ", respectively), depending on the process step. The work fluid is transported by a positive displacement pump from the feed tank.

Figure 2 shows a scheme of the unit, which is composed of three heat exchanging sections and one holding section. Numbers 0-9 outline the steps of the process. The first heater is a thermally insulated helical coil heat exchanger (Heater 1, points 1-2, internal diameter $7.75 \mathrm{~mm}$ ) connected to a counter-current hot water circuit. The following section is a focused microwave heater (Heater 2, points 3-4) with a vertical straight applicator tube housed inside a single mode cavity connected to a 2,450 $\mathrm{MHz}$ magnetron.

After the microwave section, comes the holding section, where the fluid flows through a thermally insulated coiled tube (points 5-6). There are six holding tubes available with different lengths and internal diameters as shown in Table 1. Lastly, the cooling section is another thermally insulated helical coil heat exchanger (Cooler, points $7-8$, internal diameter $9.40 \mathrm{~mm}$ ) connected to an external chiller.

\subsection{Determination of the internal volume of the product line}

For studying the mean residence time of a pasteurization process, knowledge of the internal volume of each step is important. The internal volume of the holding tubes was determined in triplicate by the gravimetric method, using a semi-analytical scale to weight the tubes, empty and filled with distilled water. The water density $(\rho)$ was calculated at average temperature [29].

Siguemoto et al. [25] used a similar gravimetric procedure to determine the internal volumes of the heat exchangers (Heater 1 and Cooler). The internal volumes of the tubing between sections were calculated based on length and internal diameter. The internal volume for the product line between points 0 and 9 in Figure 2 was determined from RTD experiments.

\subsection{RTD models}

Ideal flow models, such as perfectly mixed tank, plug flow or laminar flow, rarely reflect real systems with enough accuracy [30]. RTD models are used to better represent experimental E-curves, since they consider non-idealities in flow. Single parameter models are usually adequate to represent tubular systems [31]. In this work, five single parameter models were fitted the experimental RTD data: axial dispersion, extended tanks in series, generalized convection, PFR+CSTR association and $y$-laminar profile.

The axial dispersion model represents small deviations from the plug flow in tubular systems. This model considers that a process similar to molecular diffusion is imposed on a plug flow, named axial dispersion. The model parameter is the Peclet number, a dimensionless number defined as $P e=L v_{b} / D_{a x}$, where $L$ is the tube length, $v_{b}$ is the average velocity and $D_{a x}$ is the axial dispersion coefficient. The Peclet number represents the ratio between advection and diffusion in flow.

The development of this model is attributed to Danckwerts [32] and it has different analytical solutions depending on the system analyzed and its boundary conditions. The axial dispersion model used herein was presented by Gouvêa, Park and Giudici [33] which is a mathematical approximation of the axial dispersion model analytical 


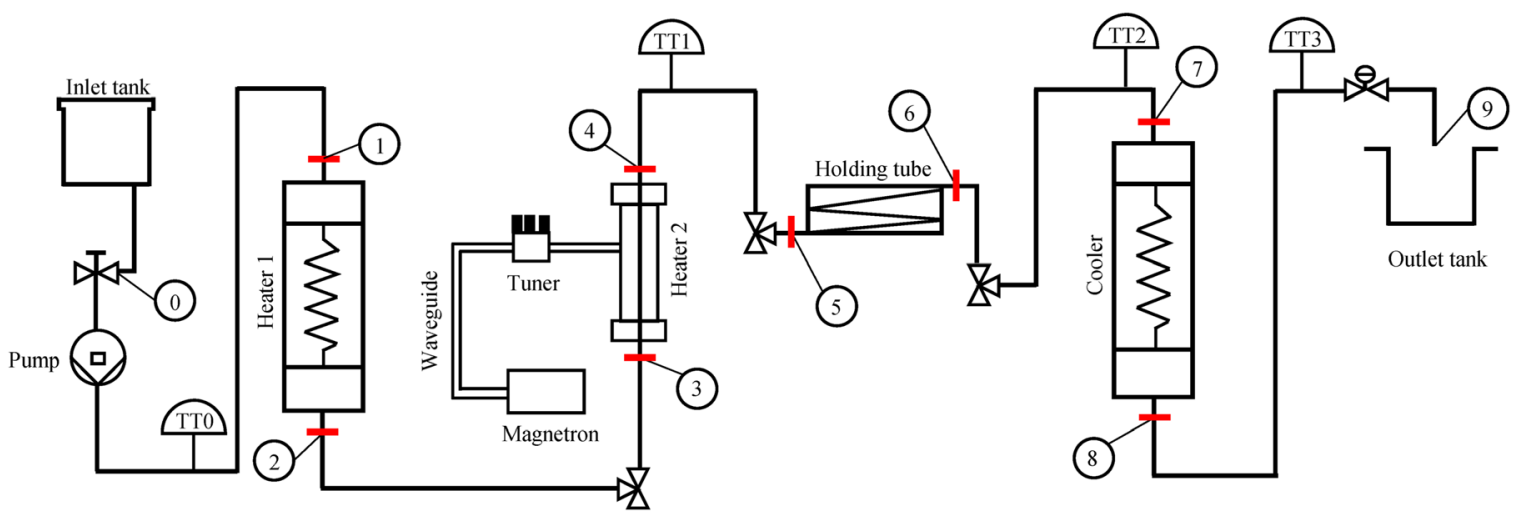

Figure 2: Schematic representation of the pasteurization unit Lab25-UHT/HTSTEHVH (MicroThermics, Raleigh, USA), adapted from Siguemoto et al. (2018).

Table 1: Internal diameters, nominal volumes and residence times at $0.5 \mathrm{~L} / \mathrm{min}$ for the holding tubes.

\begin{tabular}{lrrr}
\hline $\begin{array}{l}\text { Holding } \\
\text { tube (HT) }\end{array}$ & $\begin{array}{r}\text { Internal } \\
\text { diameter } \\
(\mathbf{m m})\end{array}$ & $\begin{array}{r}\text { Nominal } \\
\text { residence } \\
\text { time }(\mathbf{s})\end{array}$ & $\begin{array}{r}\text { Nominal } \\
\text { volume }(\mathbf{m L})\end{array}$ \\
\hline HT-1 & 9.4 & 6 & 50 \\
HT-2 & 7.7 & 6 & 50 \\
HT-3 & 9.4 & 12 & 100 \\
HT-4 & 7.7 & 12 & 100 \\
HT-5 & 7.7 & 18 & 150 \\
HT-6 & 9.4 & 18 & 150 \\
\hline
\end{tabular}

solution with closed system boundary conditions and valid for $P e>16$ (Eq. (7)).

$$
E(t)=\frac{1}{t_{m}} \sqrt{\frac{P e+1}{4 \pi\left(t / t_{m}\right)^{3}}} \exp \left(\frac{-(P e+1)\left(1-t / t_{m}\right)^{2}}{4 t / t_{m}}\right)
$$

Deviations from plug flow can also be represented by the extended tanks in series model, which is based on the RTD of perfectly mixed tanks associated in series. The parameter of this model is $N$, the number tanks. As $N$ increases the flow behavior approximates that of the plug flow reactor (PFR), but as $N$ approaches unity, the flow behavior approximates that of a continuous stirred tank reactor (CSTR) [8]. The E-curve of this model is presented in Eq. (8) [5] and the factorial of non-integer values of $N-1$ can be calculated using the Gamma function.

$$
E(t)=\frac{1}{t_{m}}\left(\frac{t}{t_{m}}\right)^{N-1} \frac{N^{N}}{(N-1) !} \exp \left(-\frac{t}{t_{m}} N\right)
$$

The generalized convection model represents deviations from the laminar tube flow, which has a parabolic velocity profile for Newtonian fluids. Ideally, the spread in the E-curve is attributed exclusively to the velocity profile. The model equation shown in Eq. (9) is a generalized form developed for helical tubes [9]. The model parameter $n$ must be greater than 2, while the ideal value for Newtonian tube flow is $n=3$.

$$
E(t)=\frac{1}{t_{m}} \frac{(n-2)^{n-1}}{(n-1)^{n-2}}\left(\frac{t}{t_{m}}\right)^{-n} t \geq \frac{(n-2)}{(n-1)} t_{m}
$$

Compartment models or combined models are based on associations of ideal reactors (PFR and CSTR), such as the PFR+CSTR series association, and can also represent deviations from the ideal laminar flow in tubular systems. The E-curve in Eq. (10) considers that the system internal volume $(V)$ has a plug flow region $\left(V_{p}\right)$ and a mixed flow region $\left(V_{m}\right)$, where $Q$ is the volumetric flow rate. The parameter of this model is $V_{p}$, while $V_{m}=V-V_{p}$ and $t_{m}=V / Q$ [5].

$$
E(t)=\frac{Q}{V_{m}} \exp \left(-\frac{Q}{V_{m}} t+\frac{V_{p}}{V_{m}}\right) \quad t \geq \frac{V_{p}}{Q}
$$

Pegoraro et al. [17] proposed an alternative RTD model based on the laminar tube flow but using a time-smoothed velocity profile characteristic of turbulent flow. Generally, an empirical approximation for turbulent tube flow is a velocity profile with order $1 / 7$. In this RTD model, a parameter $y$ was introduced to describe a non-ideal laminar velocity profile (Eq. (11)). Parameter $y$ should be lower than unity and, as it approaches zero, piston flow is obtained. The RTD of the $y$-laminar model is given by Eq. (12).

$$
\begin{gathered}
\frac{v}{v_{\max }}=\left(1-\frac{r}{R}\right)^{y} \\
E(t)=\frac{2 t_{m}}{t^{2} y}\left(\frac{t_{0}}{t}\right)^{1 / y}\left[1-\left(\frac{t_{0}}{t}\right)^{1 / y}\right] \quad t \geq \frac{2 t_{m}}{y^{2}+3 y+2}
\end{gathered}
$$

\subsection{RTD measurement and model fitting}

The RTD experiments were carried out by conductometric method at room temperature $\left(23 \pm 2{ }^{\circ} \mathrm{C}\right)$ at four flow rates $(0.5,0.7,0.9$ and $1.1 \mathrm{~L} /$ $\min )$. Water with $0.5 \mathrm{~g} / \mathrm{L}$ of sodium chloride was used as work fluid. The small concentration of salt was needed to improve the strength of the background conductivity signal. A short pulse of a saturated sodium chloride solution ( $36 \mathrm{~g} \mathrm{NaCl} / 100 \mathrm{~g} \mathrm{H}_{2} \mathrm{O}$ ) was injected at the inlet of the system in study $(0.02 \mathrm{~mL}$ in $1 \mathrm{~s})$. Injections were made at the triclamp fittings with a needle perforating the gasket between ferrules 
(Swagelok, Ohio, USA). The injection points for each system are shown in Figure 2: point 0 for the Complete System (CS), point 1 for Heater 1 (H1), point 5 for the holding tube (HT), and point 7 for the Cooler (CL). The detection cell was connected at points 9, 2, 6 and 8, respectively. The microwave section (Heater 2) residence time could not be determined with confidence because of its very small volume of $21 \mathrm{~mL}$.

The tracer injection was considered ideal (small amount in a short time). The change in electric conductivity was measured at the system outlet with a conductivity flow through cell (YSI 3445 or YSI 3255) connected to a conductivity meter YSI 3200 (YSI, Ohio, USA), and registered by data acquisition software PuTTY (PuTTY, Cambridge, England) in a personal computer. The conductivity cells are annular glass tubes with two inner electrodes (internal volume of $15 \mathrm{~mL}$ for YSI 3445 and $30 \mathrm{~mL}$ for YSI 3255). A $10.6 \mathrm{~cm}$ piece of a 3/8" tube with a triclamp ferrule was attached to the cell inlet to allow its connection to the system outlet using a gasket and clamp; thus, the "detection cell" consisted of the $3 / 8$ " tube and the conductivity flow through cell. The outlet of the cell had a silicon tube open to the atmosphere.

Conductivity was registered every $1 \mathrm{~s}$, at least. For each flow rate and system, three repetitions were made. In the case of the RTD of the detection cell, five repetitions were made because of the short residence time. In this case, the tracer was injected trough the gasket of the $3 / 8$ " tube connected to the conductivity flow through cell.

For each experiment, $E(t), E_{\theta}(\theta)$ and $t_{m}$ were calculated according to the description in Section 1. Since the electrical conductivity of a $\mathrm{NaCl}$ solution can be assumed to be linearly dependent on its concentration, for a given room temperature between 17 and $31^{\circ} \mathrm{C}$, the conductivity data were used as $C(t)$ in Eq. (1) to obtain $E(t)$ [8]. The integrals were numerically solved by the trapezoidal method using software Excel 2016 (Microsoft, Redmond, USA).

For the complete system, the maximum and minimum residence times were determined. The minimum residence time was obtained when the conductivity cell started to register an increase and the maximum residence time was obtained when the conductivity returned to its original average value. Since the start-up of the equipment is made with water before processing a food product, the knowledge of the maximum and minimum residence times is important to know when all the water is flushed out of the system when the feed is switched to the product tank.

2.4.1 Correction for non-ideal tracer detection: When adjusting the RTD models to the experimental data, the procedure proposed by Gutierrez et al. [8] was used to correct the non-ideal tracer detection. It is considered that the recorded RTD data is actually the convolution of the RTD of the system with the RTD of the detection cell.

Initially, pulse experiments were performed to determine the RTD of the detection cell $\left(E_{\text {cell }}\right)$, its mean residence time and the parameter of the model with the best fit (axial dispersion model or tanks-in-series). Next, as illustrated in Figure 3, an experiment with the same fluid at the same flow rate was performed to obtain RTD data from the $\operatorname{system}\left(E_{\text {exp }}\right)$, which includes the interference from the cell. One of the five RTD models proposed in Section 2.3 was selected to represent the real E-curve of system $(E)$ with a given mean residence time and parameter. The convolution of signals was applied between $E$ and $E_{\text {cell }}$ and then the $E_{\text {conv }}$ curve obtained was fitted to the experimental data by the estimation of the RTD model parameter and mean residence time of the system.

The five RTD models presented in Section 2.3 were iteratively adjusted by non-linear regression on $E_{\text {conv }}(t)$ in terms of the sum of squared errors (SSE) between the experimental data and the convoluted model prediction (Eq. (13)). The model parameter and the system
1) Adjust model to RTD of detection cell

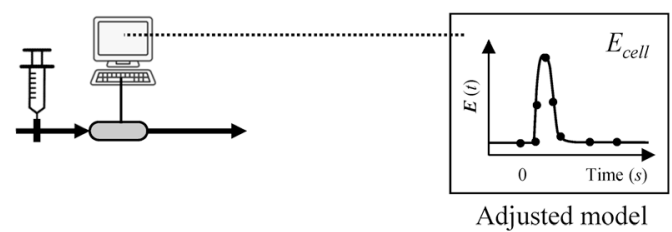

2) Obtain experimental RTD of system

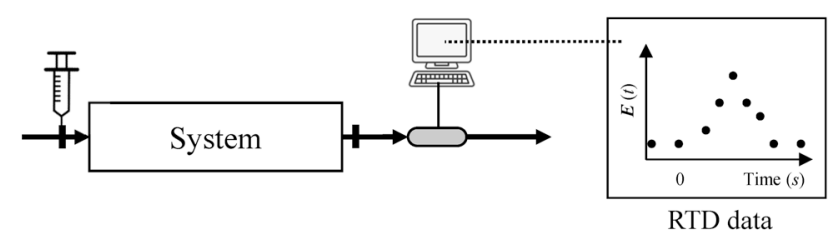

3) Adjust convoluted RTD model

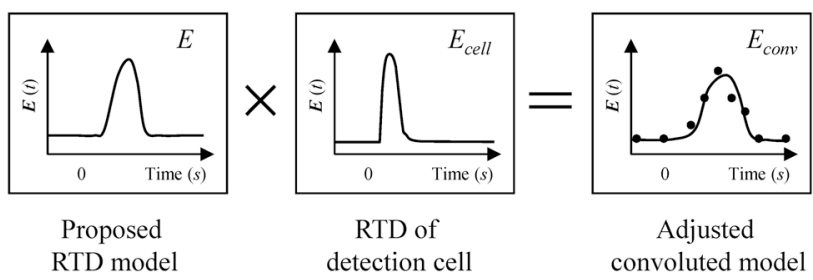

Figure 3: Procedure to correct non-ideal tracer detection, adapted from Gutierrez et al. (2010).

mean residence time $t_{m}$ were adjusted simultaneously, except for the PFR+CSTR association model in which the mean residence time was obtained indirectly by the adjusted CSTR and PFR volumes.

$$
\mathrm{SSE}=\sum_{i=1}^{n}\left(E_{\text {exp }, i}(t)-E_{\text {conv }, i}(t)\right)^{2}
$$

Using an initial guess for the model parameter ( $P e, N, n, V_{p}$ or $y$, depending on the model) and $t_{m}$, the SSE was minimized with Solver in Excel 2016 (Microsoft, Redmond, USA) using a generalized reduced gradient algorithm. After that, the adjusted model parameters were correlated with the Reynolds number. The mean residence time was also correlated with the flow rate to determine the active volume of the system $V_{A}$, considering that $t_{m}=V_{A} / Q$.

The Reynolds number $(R e)$ was calculated with Eq. (14), for the holding tubes and heat exchangers. The internal diameters $\left(d_{i}\right)$ considered herein are shown in Section 2.1 for the heat exchangers and in Table 1 for the holding tubes. The average velocity was calculated from the ratio between the flow rate and the crosssectional area of the tube $\left(v_{b}=4 \quad Q /\left(\begin{array}{ll}\pi & \left.\left.d_{i}^{2}\right)\right)\end{array}\right)\right.$ and the kinematic viscosity of the work fluid was calculated by the ratio between viscosity and density $(v=\mu / \rho)$. Viscosity was calculated at average fluid temperature using correlations valid for water since the $\mathrm{NaCl}$ concentration was small [29].

$$
\operatorname{Re}=\frac{d_{i} v_{b}}{v}
$$

The Dean number $(D e)$ is relevant to the study of helical tubes, as it expresses the magnitude of inertial and centrifugal forces to viscous forces. Using values of $R e$, the internal radius of the tube $(R)$ and the radius of curvature $\left(R_{C}\right)$, the Dean number was calculated with Eq. (15) [34]. 


$$
D e=\operatorname{Re} \sqrt{\frac{R}{R_{C}}}
$$

\section{Results and discussion}

The Dean number and Reynolds number ranges are shown in Table 2 for the holding tubes, Heater 1 and Cooler. When the Dean number is greater than 10, the effects of the secondary flow are relevant as they promote reduction in axial dispersion [10]. Reynolds numbers suggest laminar/transition flow regime. In their experiments with water in helical tubes, Koutsky and Adler [12] showed that the transition from laminar to turbulent flow is smooth and occurs over a range of Reynolds numbers between 3000 and 7000.

The internal volume of the product line is shown in Table 3, according to the procedure described in Section 2.2. The determined volumes of the holding tubes were lower than their nominal volumes. This suggests a small loss of internal volume when constructing the helical tubes from the straight tubes. Owing to that, the measured volumes were considered as the real internal volumes of the holding tubes. The internal volumes of the heat exchangers (Heater 1 and Cooler) and the complete system were determined by Siguemoto et al. [23] and are shown in Table 3 as well.

\subsection{RTD of the detection cells}

The RTD model that presented the best fit for both conductivity cells was the axial dispersion model, as shown in Figure 4A, B for the flow rate of $0.5 \mathrm{~L} / \mathrm{min}$, as an example. The scattering of experimental data was due to the short residence time. For each experimental run, the Peclet number was adjusted along with mean residence time in

Table 2: Reynolds number and Dean number ranges for Holding Tubes (HT), Heater 1 (H1) and Cooler (CL).

\begin{tabular}{lrr}
\hline System & Reynolds number $(-)$ & Dean number $(-)$ \\
\hline HT-1 & $1307-3369$ & $496-1280$ \\
HT-2 & $1271-3369$ & $524-1390$ \\
HT-3 & $1482-3224$ & $747-1625$ \\
HT-4 & $1259-3288$ & $561-1464$ \\
HT-5 & $1453-3930$ & $462-1251$ \\
HT-6 & $1377-3178$ & $477-1100$ \\
H1 & $1815-4571$ & $832-2094$ \\
CL & $1575-4238$ & $749-2016$ \\
\hline
\end{tabular}

Table 3: Nominal volumes, measured volumes and active volumes of the Holding Tubes (HT), Heater $1(\mathrm{H} 1)$, Cooler $(\mathrm{CL})$ and complete system (CS).

\begin{tabular}{lrrrr}
\hline System & $\begin{array}{r}\text { Nominal } \\
\text { volume } \\
(\mathrm{mL})\end{array}$ & $\begin{array}{r}\text { Measured } \\
\text { volume }(\mathrm{mL})\end{array}$ & $\begin{array}{r}\text { Active } \\
\text { volume } \\
(\mathrm{mL}) \text { axial } \\
\text { dispersion }\end{array}$ & $\begin{array}{r}\text { Active } \\
\text { volume }(\mathrm{mL}) \\
\boldsymbol{y} \text {-laminar }\end{array}$ \\
\hline HT-1 & 50 & $43.0 \pm 1.7$ & 42.1 & 41.8 \\
HT-2 & 50 & $44.3 \pm 0.3$ & 42.2 & 41.7 \\
HT-3 & 100 & $85.7 \pm 0.6$ & 63.9 & 64.4 \\
HT-4 & 100 & $87.1 \pm 0.8$ & 77.2 & 78.0 \\
HT-5 & 150 & $120 \pm 1$ & 116 & 117 \\
HT-6 & 150 & $125 \pm 1$ & 107 & 110 \\
H1 & - & $437^{\mathrm{a}}$ & $406^{\mathrm{b}}$ & $406^{\mathrm{b}}$ \\
CL & - & $696^{\mathrm{a}}$ & $644^{\mathrm{b}}$ & $644^{\mathrm{b}}$ \\
$\mathrm{CS}$ & - & - & 1823 & 1951 \\
\hline
\end{tabular}

${ }^{\mathrm{a}}$ From Siguemoto et al. (2018).

${ }^{b}$ From generalized convection model.

the model fitting. Since Eq. (7) is valid only for $P e>16$ and values smaller than 16 were obtained, these Peclet numbers cannot be used for dispersion calculus. However, Eq. (7) still represents a consistent E-curve for $P e<16$.

The relationship between the flow rate and the logarithm of Peclet number was evaluated and the results are shown in Figure 4C, D. Since it was not possible to detect a significant trend, a mean value of $\log (P e)$ was considered for conductivity cells YSI $3445(\log (P e)=0.421)$ and YSI $3255(\log (P e)=0.706)$.

The flow rate dependence of the mean residence time is shown in Figure 4E, F for conductivity cells YSI 3445 and YSI 3255, respectively. The correlations obtained are presented in Eq. (16) for YSI 3445 and Eq. (17) for YSI 3255. Generally, the correlation between $t_{m}$ and $Q$ is expected to be $t_{m}=V_{A} / Q$, where $V_{A}$ is the active volume of the system. Nevertheless, Eqs. (16) and (17) do not have that form because the conductivity electrodes are inside the conductivity cell and not at its exit.

$$
\begin{array}{lll}
t_{m}(\mathrm{~s})=84.7 & Q(\mathrm{~mL} / \mathrm{s})^{-1.33} & R^{2}=0.993 \\
t_{m}(\mathrm{~s})=92.2 & Q(\mathrm{~mL} / \mathrm{s})^{-1.30} & R^{2}=0.960
\end{array}
$$

\subsection{RTD of the holding tubes}

The RTD of the holding tubes was determined according to Section 2.5. Models that presented the best fits were the axial dispersion and the $y$-laminar model. Due to the large amount of data, only the results of Holding Tube 5 (HT-5) 

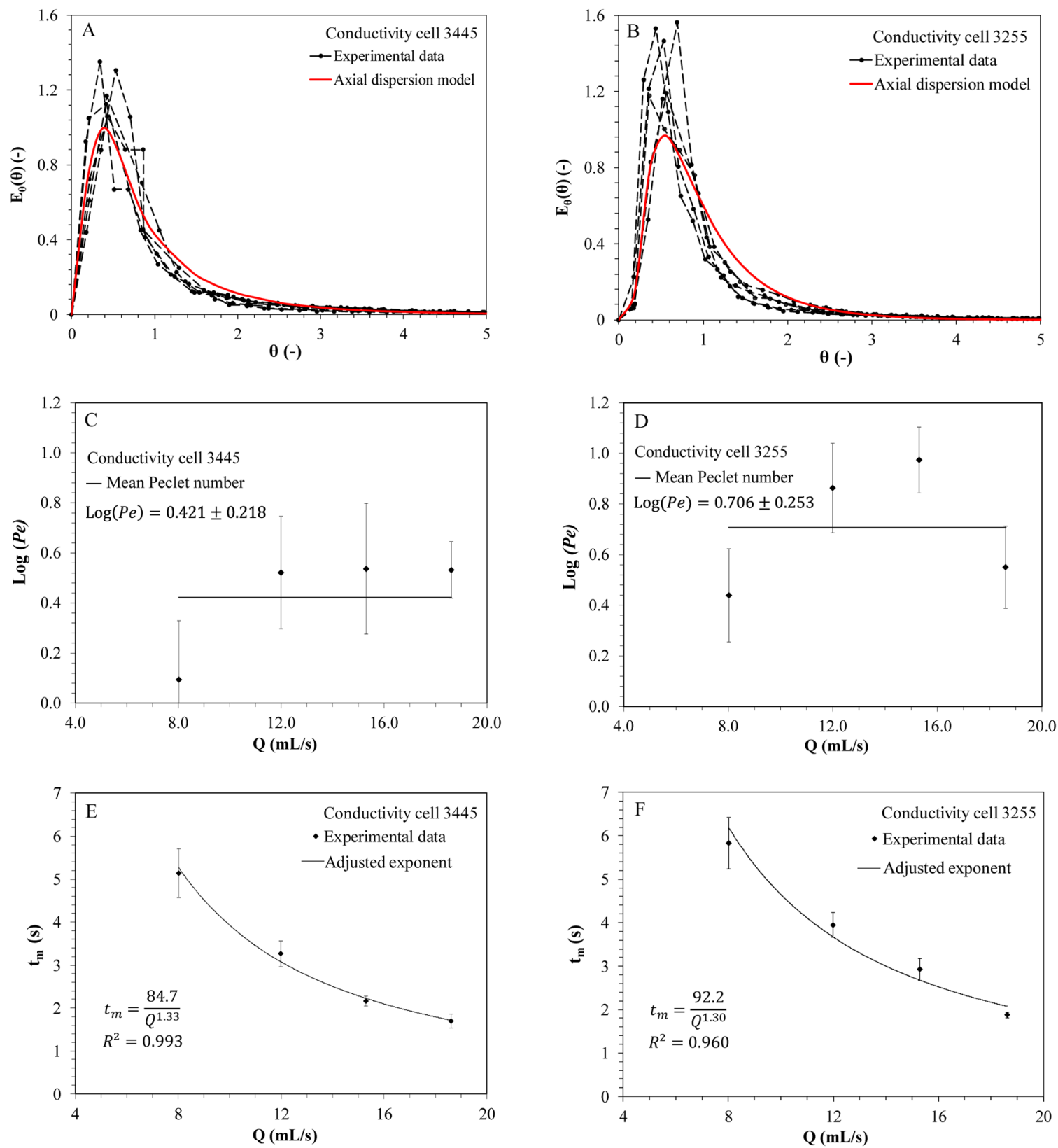

Figure 4: Residence time distribution results of the detection cells: fitting of the axial dispersion model at $0.5 \mathrm{~L} / \mathrm{min}$ for the conductivity cell YSI 3445 (A) and YSI 3255 (B); Peclet number as a function of flow rate for conductivity cell YSI 3445 (C) and YSI 3255 (D); flow rate dependence on the mean residence time for conductivity cell YSI 3445 (E) and YSI 3255 (F).

are shown in Figure 5; however, the following discussion is valid for the other holding tubes, as well.

Examples of convolution and model adjustment with the axial dispersion model and $y$-laminar model is shown in Figure 5A, B, respectively, for flow rate $0.7 \mathrm{~L} / \mathrm{min}$. Convolution was made with the E-curve of the detection cell YSI 3445 for the same flow rate. The signal distortion caused by the detection cell is evident, since the convoluted model curve is displaced forward in time and has a much larger dispersion.

Model parameters dependence on the Reynolds number is shown in Figure 5C, D. For the axial dispersion model (Figure 5C), the Peclet number showed a decreasing trend with an increasing Reynolds; however, the relationship between the Peclet and the Reynolds number should be crescent, since an increase in flow rate 

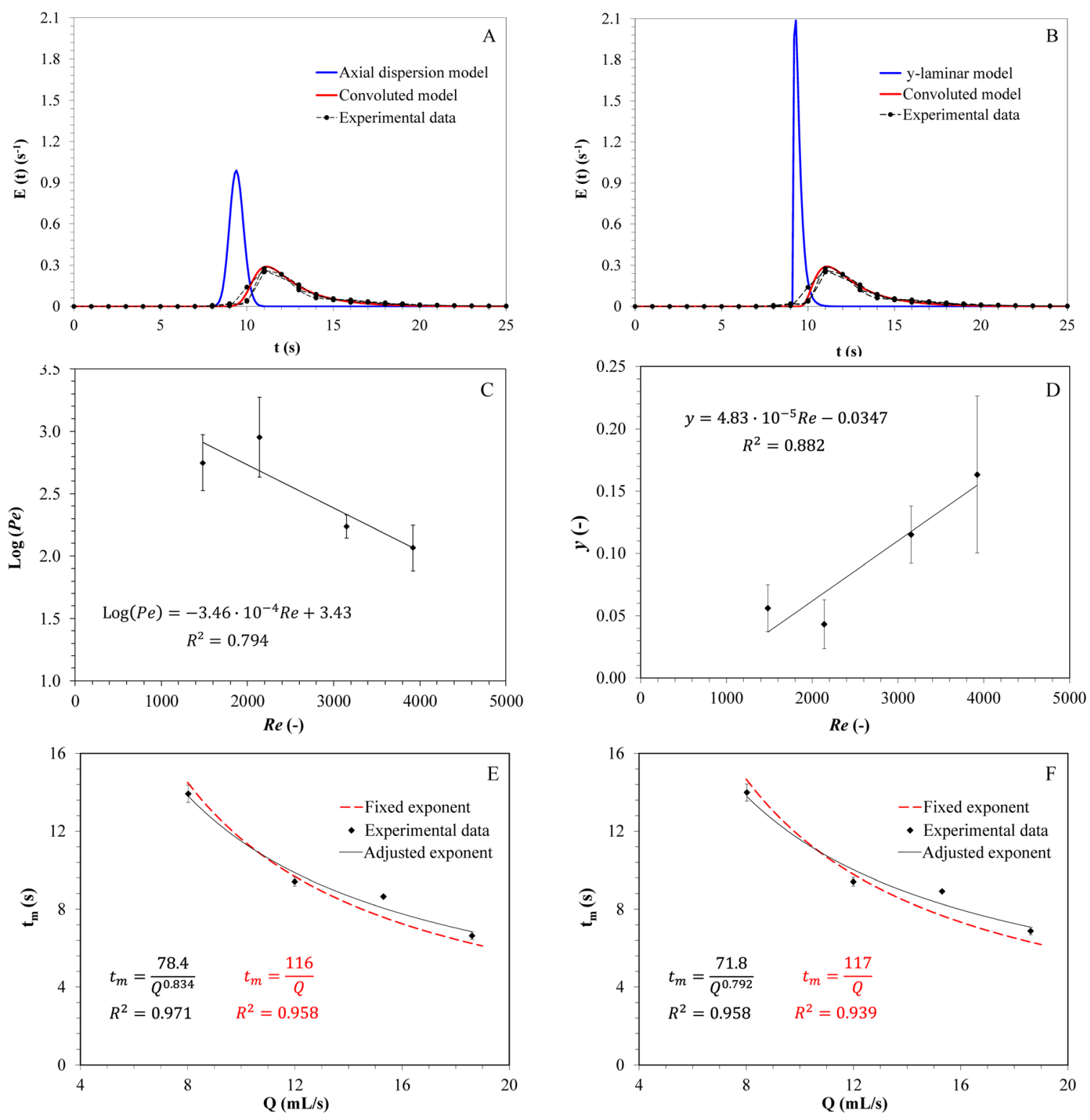

Figure 5: Residence time distribution results of Holding Tube 5 (HT-5): fitting of the axial dispersion model at $0.7 \mathrm{~L} / \mathrm{min}(\mathrm{A})$; fitting of the $y$-laminar model at $0.7 \mathrm{~L} / \mathrm{min}(\mathrm{B})$; logarithm of Peclet number as a function of Reynolds number (C); parameter $y$ as a function of Reynolds number (D); flow rate dependence on the mean residence time according to axial dispersion (E) and $y$-laminar (F).

Table 4: Relationship between the adjusted parameter of the RTD model and Reynolds number for all holding tubes.

\begin{tabular}{lll}
\hline System & Axial dispersion & $y$-Laminar \\
\hline HT-1 & $\log (P e)=4.90-6.39 \times 10^{-4} R e$ & $y=-0.0116+3.55 \times 10^{-5} R e$ \\
HT-2 & $\log (P e)=4.89-5.03 \times 10^{-4} R e$ & $y=0.0898-2.35 \times 10^{-5} R e$ \\
HT-3 & $\log (P e)=2.67-2.50 \times 10^{-4} R e$ & $y=0.0515+2.96 \times 10^{-5} R e$ \\
HT-4 & $\log (P e)=3.05-2.73 \times 10^{-4} R e$ & $y=0.0718+1.75 \times 10^{-5} R e$ \\
HT-5 & $\log (P e)=3.43-3.46 \times 10^{-4} R e$ & $y=-0.0347+4.83 \times 10^{-5} R e$ \\
HT-6 & $\log (P e)=3.38-4.04 \times 10^{-4} R e$ & $y=0.0989+8.83 \times 10^{-6} R e$ \\
\hline
\end{tabular}


Table 5: Relative difference between the mean residence time of the detection cells and systems (Holding Tube 5 and Cooler).

\begin{tabular}{|c|c|c|c|c|c|c|}
\hline \multirow[t]{2}{*}{$Q(\mathrm{~L} / \mathrm{min})$} & \multicolumn{3}{|c|}{ Flow cell YSI 3445} & \multicolumn{3}{|c|}{ Flow cell YSI 3255} \\
\hline & $t_{m 3445}(s)$ & $t_{m H T-5}(\mathrm{~s})$ & Difference (\%) & $t_{m 3255}(\mathrm{~s})$ & $t_{m \text { cooler }}(\mathrm{s})$ & Difference (\%) \\
\hline 0.5 & 5.31 & 14.5 & 63.3 & 6.15 & 80.3 & 92.3 \\
\hline 0.7 & 3.11 & 9.68 & 67.9 & 3.65 & 53.7 & 93.2 \\
\hline 0.9 & 2.25 & 7.59 & 70.3 & 2.66 & 42.1 & 93.7 \\
\hline 1.1 & 1.73 & 6.24 & 72.2 & 2.06 & 34.6 & 94.0 \\
\hline
\end{tabular}
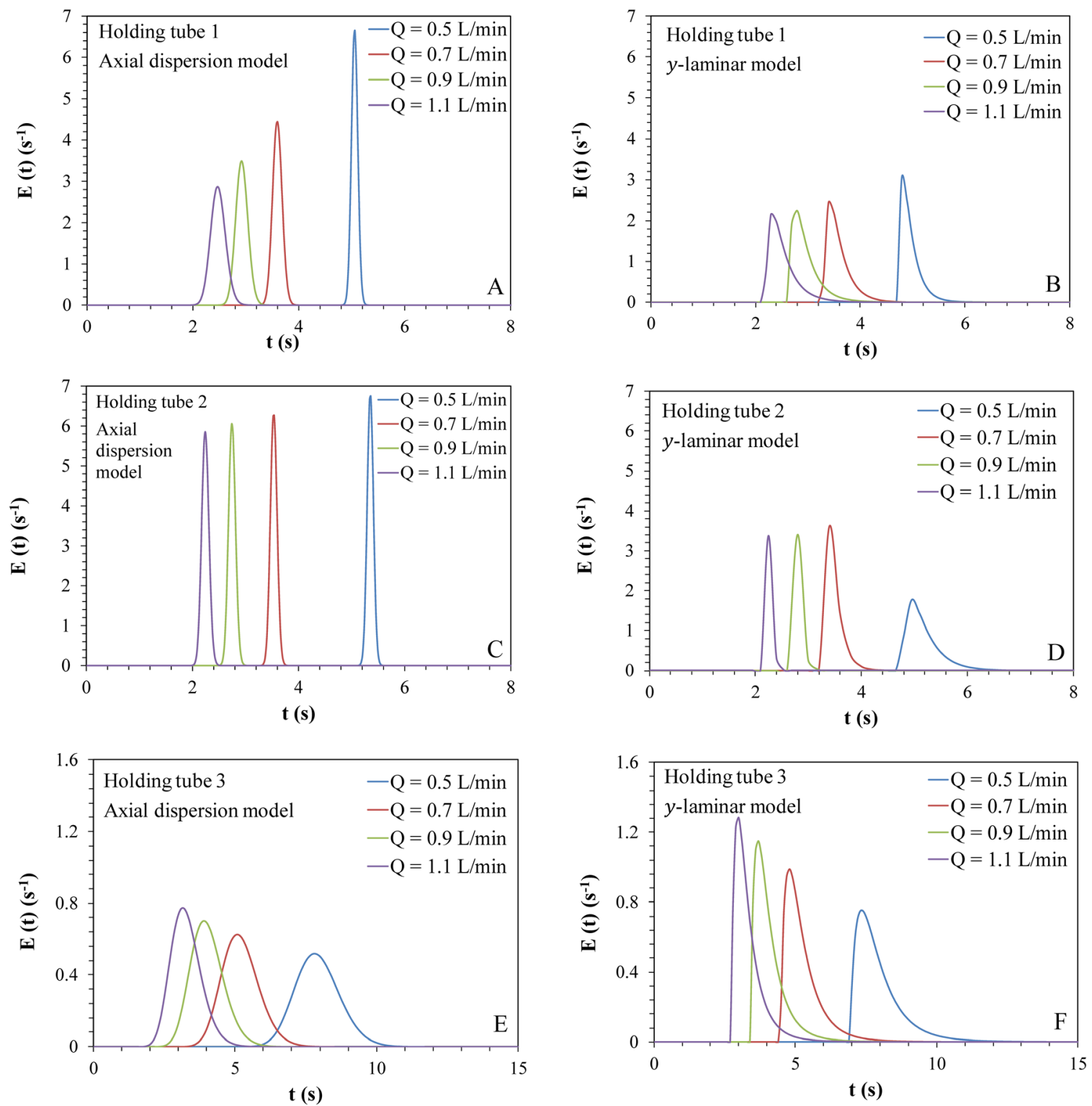

Figure 6: Effect of the flow rate on the adjusted RTD curves of Holding Tube 1 according to the axial dispersion model (A) and $y$-laminar model (B); Holding Tube 2 according to the axial dispersion model (C) and $y$-laminar model (D); and Holding Tube 3 according to the axial dispersion model (E) and $y$-laminar model (F). 

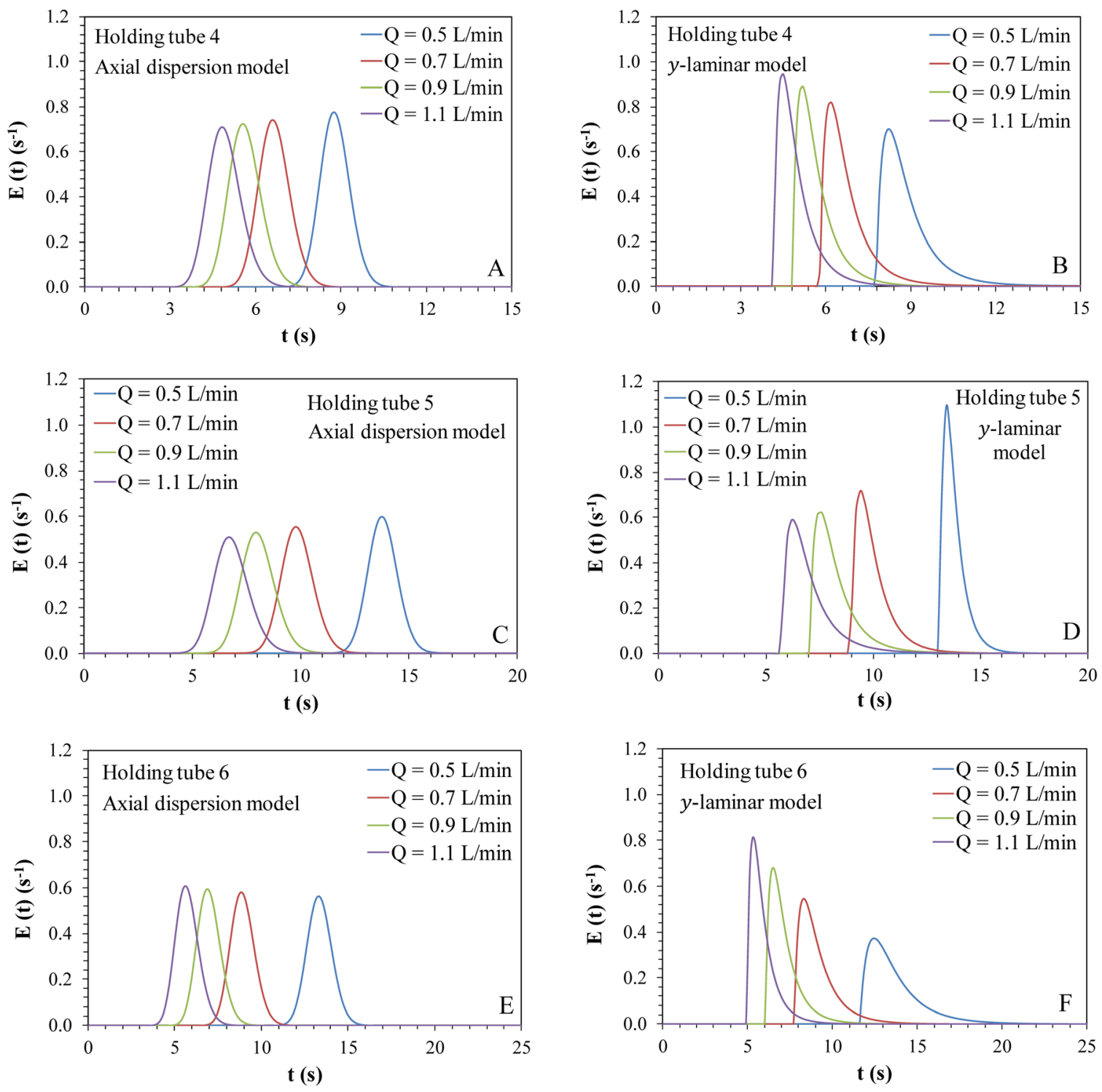

Figure 7: Effect of the flow rate on the adjusted RTD curves of Holding Tube 4 according to the axial dispersion model (A) and $y$-laminar model (B); Holding Tube 5 according to the axial dispersion model (C) and $y$-laminar model (D); and Holding Tube 6 according to axial the dispersion model (E) and $y$-laminar model (F).

induces turbulence. In case of the $y$-laminar model (Figure 5D), $y$ presented a crescent trend with an increasing Reynolds. According to Pegoraro et al. [17], parameter $y$ should decrease with Reynolds, since $y$ decreases with increased turbulence. These differences must be the result of the secondary flow caused by the bends, since this expected behavior is valid for straight tubes. Table 4 shows the relationship between $y$ and $\log (P e)$ with Reynolds number for all tubes.

The mean residence time dependence on the flow rate is shown in Figure 5E, F. In a first adjustment, the exponent of flow rate was free, as can be seen in the "Adjusted exponent" curves. For comparison, a second adjustment was made setting the flow rate exponent to one, showed by the "Fixed exponent" curves. After this second adjustment, Eqs. (18) and (19) were obtained and compared with the expected equation $t_{m}=V_{A} / Q$. Consequently, the active volume of HT-5 is $116 \mathrm{~mL}$ according to the axial dispersion and $117 \mathrm{~mL}$ according to the $y$-laminar model. The active volumes of all tubes are shown in Table 3 according to both models, which were obtained following the same procedure.

$$
t_{m}=\frac{116 \mathrm{~mL}}{Q} \quad R^{2}=0.958
$$



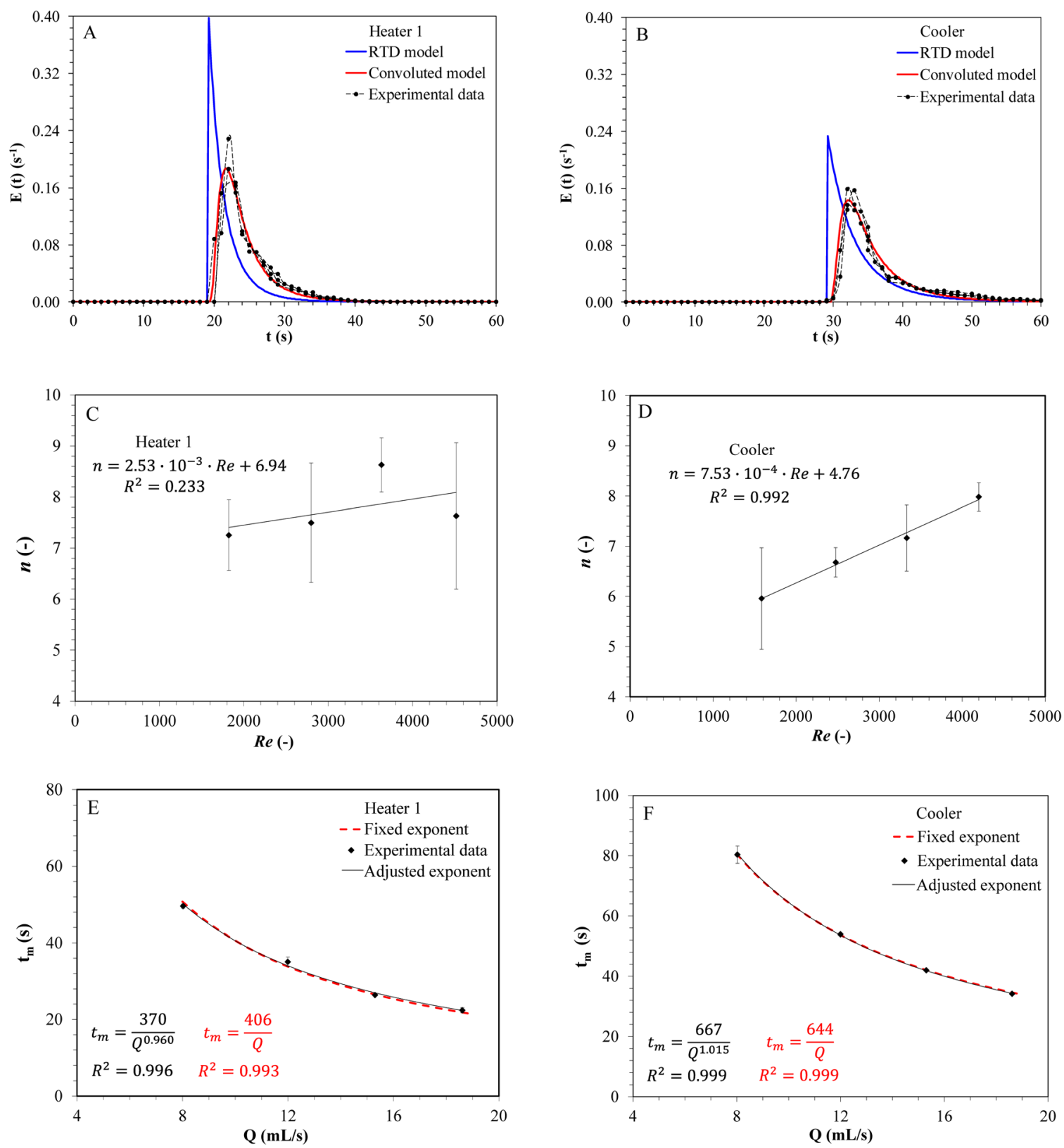

Figure 8: Residence time distribution results of the heat exchangers (Heater 1 and Cooler): fitting of the generalized convection model at $1.1 \mathrm{~L} /$ min for Heater 1 (A) and Cooler (B); parameter $n$ as a function of Reynolds number for Heater 1 (C) and Cooler (D); flow rate dependence on the mean residence time for Heater $1(\mathrm{E})$ and Cooler $(\mathrm{F})$.

$$
t_{m}=\frac{117 \mathrm{~mL}}{Q} \quad R^{2}=0.939
$$

Comparing the active volumes with the measured volumes shown in Table 3, HT-1, HT-2 and HT-5 can be considered not to have significant dead volume because the difference was less than 5\%. For the other holding tubes (HT-3, HT-4 and HT-6) this difference was higher than 5\%, indicating that they may have a significant presence of recirculation zones.
Table 5 presents the relative difference between the mean residence time adjusted for HT-5 and the mean residence time adjusted for the detection cell (YSI 3445) as a function of the flow rate. The relative differences presented in this table indicate that the mean residence time of the detection cell corresponds to a maximum of $37 \%$ and a minimum of $28 \%$ of the mean residence time of holding tube 5. Fillaudeau et al. [35] verified that the distortion of the signal by the cell can be neglected if it does not exceed 

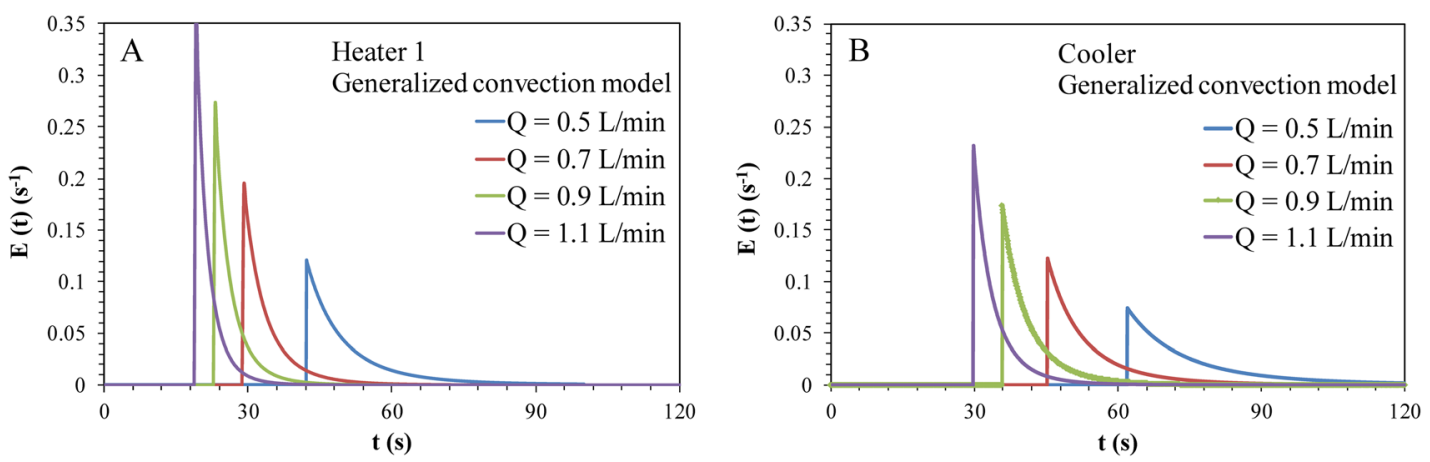

Figure 9: Effect of the flow rate on the adjusted RTD curves of Heater 1 (A) and Cooler (B) according to the generalized convection model.

$1 \%$ of the mean residence time of the process. Therefore, convolution is mandatory to correct the distortion in the measured RTD data for the holding tubes.

Lastly, adjusted RTD model curves as a function of the flow rate are shown in Figures 6 and 7 for all holding tubes, according to the axial dispersion model and $y$-laminar model. As the flow rate increases, the tracer exits the system faster and with less dispersion. The results are presented for both models because they are useful for simulating a holding tube taking into account the dispersion either axially $(\mathrm{Pe})$ or radially $(y)$.

\subsection{RTD of the heat exchangers}

The RTD model that presented the best fit for both heat exchangers (H1 and $\mathrm{CL}$ ) was the generalized convection model. Examples of convolution and model adjustment are shown in Figure 8A,B for Heater 1 and Cooler, respectively, at a $1.1 \mathrm{~L} / \mathrm{min}$ flow rate. Convolution was made with the E-curve of the detection cell YSI 3255 for the same flow rate. In this case, the signal distortion caused by the flow through the detection cell was smaller than the distortion observed for holding tube 5 in Figure 5A, B, because the internal volumes of the heat exchangers are greater than the internal volumes of the holding tubes.

The influence of the Reynolds number on model parameter $n$ is shown in Figure 8C, D for Heater 1 and Cooler, respectively. Parameter $n$ is related to the breakthrough time $\theta_{0}=(n-2) /(n-1)$, which is the moment when the fastest particle exits the system [36]. Its theoretical value is $\theta_{0}=0.5(n=3)$ for the Newtonian laminar flow in a straight tube.

The values of $n$ obtained herein are above 4.0 (Figure 8C, D), which yield values above 0.5 for the breakthrough time (between 0.77 and 0.86 ). The limiting case is $\theta_{0}=1.0$, in which a Dirac pulse is obtained (plug flow). Trivedi and Vasudeva [37] obtained values of $\theta_{0}$ between 0.59 and 0.66 for laminar flow in helical coils. When $\theta_{0}>0.5$, the velocity profile becomes flatter compared to the typical parabolic profile of laminar flow in straight tubes.

The mean residence time dependence on the flow rate is shown in Figure 8E, F for Heater 1 and Cooler, respectively. In the first adjustment, the flow rate exponent was free (adjusted exponent curves). A second adjustment was made setting the flow rate exponent to one, providing Eqs. (20) and (21) for Heater 1 and Cooler, respectively.

$$
\begin{array}{ll}
t_{m}=\frac{406}{Q} & R^{2}=0.993 \\
t_{m}=\frac{644}{Q} & R^{2}=0.999
\end{array}
$$

The adjusted equations were compared to the expected correlation $t_{m}=V_{A} / Q$ to obtain the active volume of the heat exchangers, yielding a value of $406 \mathrm{~mL}$ for Heater 1 and $644 \mathrm{~mL}$ for the Cooler. Comparing the active volumes with the measured volumes presented in Table 3, it is possible to say that Heater 1 has a dead volume of $437-406=31 \mathrm{~mL}(7.1 \%$ of measured volume $)$ and the Cooler has a dead volume of $696-644=52 \mathrm{~mL}(7.5 \%$ of measured volume).

The relative difference between the mean residence time adjusted for the Cooler and the mean residence time adjusted for the detection cell (YSI 3255) as a function of the flow rate is shown in Table 5. The values presented in this table indicate that the mean residence time of the detection cell corresponds to a maximum of $7 \%$ and a minimum of $6 \%$ of the mean residence time of the Cooler. Based on Fillaudeau et al. [35], the convolution procedure is necessary to correct the signal distortion. The same analysis is valid for Heater 1, which has a smaller volume than the Cooler. 

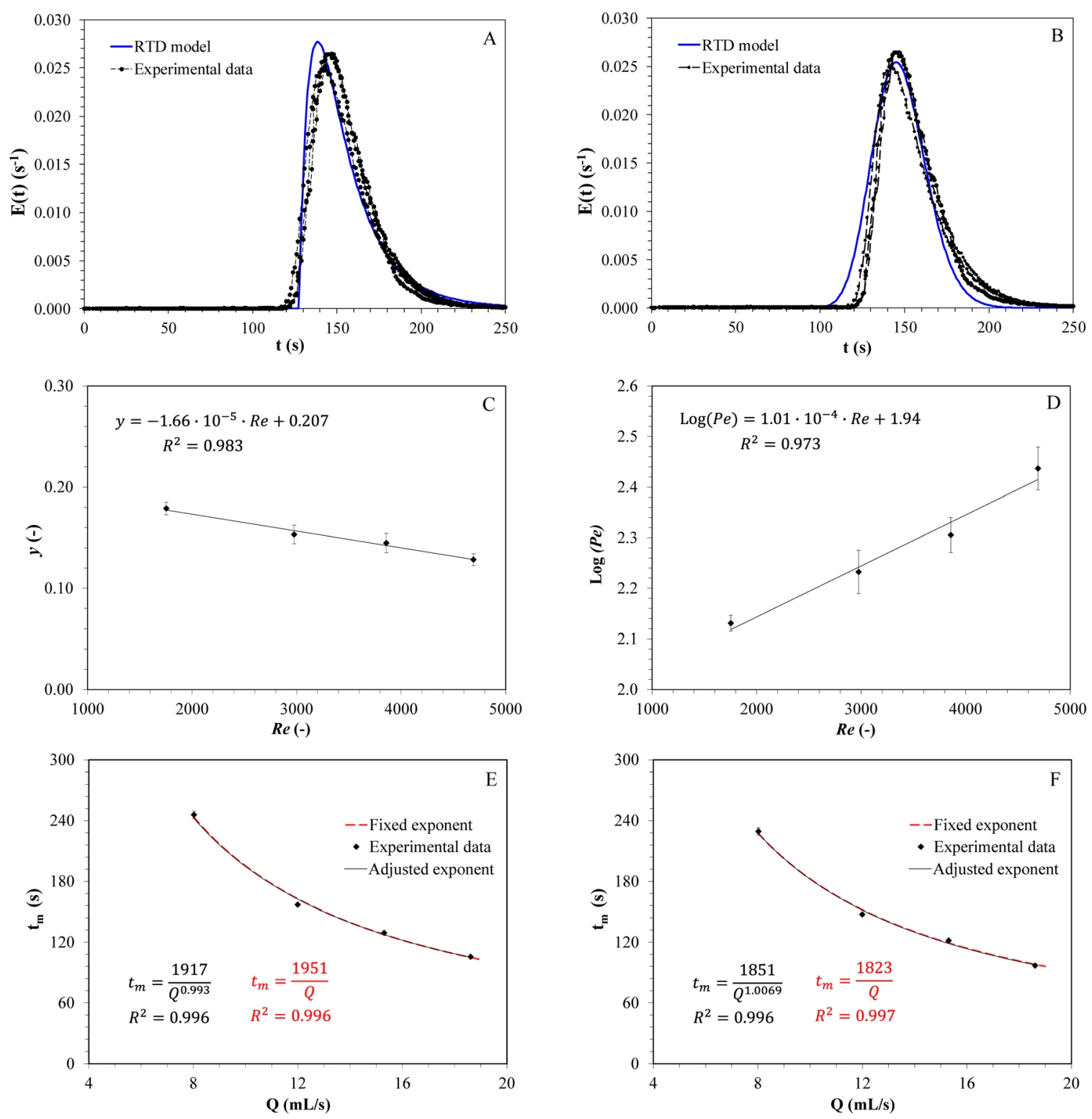

Figure 10: Residence time distribution results of the Complete System (CS): fitting of the $y$-laminar model at $0.7 \mathrm{~L} / \mathrm{min}$ (A); fitting of the axial dispersion model at $0.7 \mathrm{~L} / \mathrm{min}$ (B); parameter $y$ as function of Reynolds number (C); logarithm of Peclet number as a function of Reynolds number (D); flow rate dependence with the mean residence time for the $y$-laminar model (E) and axial dispersion model (F).

Table 6: Minimum, mean and maximum residence time $\left(t_{\min }, t_{m}\right.$, $t_{\max }$ ) of Complete System in function of flow rate.

\begin{tabular}{lrrr}
\hline $\boldsymbol{Q}(\mathrm{L} / \mathbf{m i n})$ & $\boldsymbol{t}_{\min }(\mathbf{s})$ & $\boldsymbol{t}_{\boldsymbol{m}}(\mathbf{s})$ & $\boldsymbol{t}_{\max }(\mathbf{s})$ \\
\hline 0.5 & $192 \pm 2$ & $237 \pm 5$ & $358 \pm 4$ \\
0.7 & $127 \pm 3$ & $154 \pm 1$ & $230 \pm 2$ \\
0.9 & $106 \pm 2$ & $127 \pm 2$ & $185 \pm 2$ \\
1.1 & $88 \pm 2$ & $105 \pm 3$ & $148 \pm 1$ \\
\hline
\end{tabular}

Adjusted RTD curves for the generalized convection model are shown in Figure 9A, B for Heater 1 and Cooler. For both cases, the E-curve showed a larger spread for lower flow rates, as expected.

\subsection{RTD of the complete system}

The RTD model that presented best fit for the complete system was the $y$-laminar, closely followed by axial dispersion. Examples of model adjustment for the 

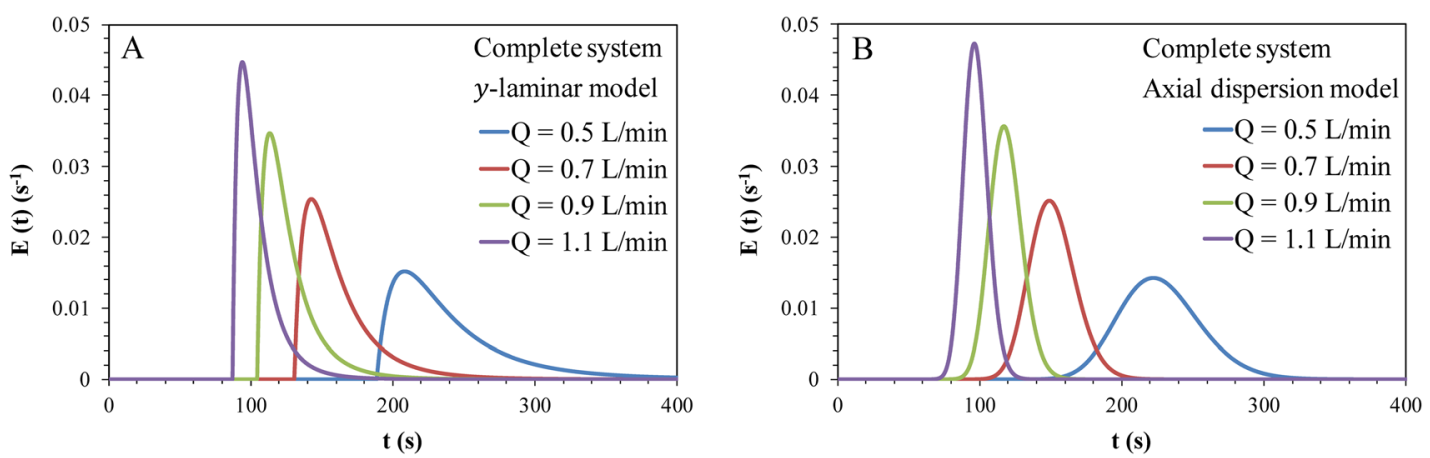

Figure 11: Effect of flow rate on the adjusted RTD curves of complete system according to the $y$-laminar model (A) and axial dispersion model (B).

$y$-laminar and axial dispersion models are shown in Figure 10A, B, respectively. The $y$-laminar model adjusted better the beginning and the end of the E-curve, while the axial dispersion model better adjusted the peak of E-curve.

Convolution was not necessary for the complete system, because the mean residence time of the detection cell (YSI 3445) corresponds to a maximum of $2.2 \%$ of the mean residence time of the complete system. Moreover, the experimental E-curve did not present a significant distortion compared to the theoretical curve.

Reynolds number dependence for parameters $y$ and $P e$ is shown in Figure 10C, D, respectively. For both models, the experimental results are coherent, i.e., parameter $y$ decreasing with increasing Reynolds (Figure 10C) and Peclet number increasing with increasing Reynolds number (Figure 10D). Since parameter $y$ presented values under 0.2 and Peclet number was higher than $10^{2}$, it can be said that there is a small deviation from the plug flow for the whole process [17]. Nevertheless, this model simplification may not hold for processing temperatures because of the lower viscosity.

Influence of the flow rate on the mean residence time is shown in Figure 10E, F. The procedure used for holding tubes and heat exchangers was applied to the complete system using free and fixed flow rate exponents. After this second adjustment, Eqs. (22) and (23) were obtained according to the $y$-laminar and axial dispersion models, respectively, providing the active volumes reported in Table 3.

$$
\begin{gathered}
t_{m}=\frac{1951}{Q} R^{2}=0.996 \\
t_{m}=\frac{1823}{Q} \quad R^{2}=0.997
\end{gathered}
$$

Minimum and maximum residence times of the process $\left(t_{\min }\right.$ and $t_{\max }$, respectively) were determined according to Section 2.4. They are particularly important for process operation. The minimum residence time is related to the product safety (inactivation of the target of thermal process in the regions of higher velocities) and maximum residence time is important for process start-up and product quality (overprocessing). The results are shown in Table 6 as a function of the flow rate. The mean residence time $\left(t_{m}\right)$ values presented in this table were the ones obtained through the $y$-laminar model. At last, adjusted RTD curves are shown in Figure 11A, B according to the $y$-laminar and axial dispersion models, respectively.

\section{Conclusions}

The method proposed in this work to correct distortions in measured RTD data introduced by the in-line detection cell was successful. The distortion was found to be more significant when the internal volume of the detection cell was similar to the internal volume of the analyzed system, which can be clearly observed for the holding tubes and heat exchangers. In the case of the complete system, due to its larger internal volume, the convolution procedure was unnecessary. The results showed the importance of correcting distortions in RTD data in systems with short residence time such as holding tubes for pasteurization processes.

Acknowledgments: This research was supported by FAPESP (São Paulo Research Foundation - grant 2006/01628-0, 2013/07914-8), CNPq (Conselho Nacional de Desenvolvimento Científico e Tecnológico/Brazilian National Council of Scientific and Technological Development - grant 311868/2018-5), and CAPES (Coordenação de Aperfeiçoamento de Pessoal de Nível Superior/Coordination for the Improvement of Higher Education Personnel Finance code 001). 
Author contribution: All the authors have accepted responsibility for the entire content of this submitted manuscript and approved submission.

Research funding: This research was supported by FAPESP (São Paulo Research Foundation - grant 2006/01628-0, 2013/ 07914-8), CNPq (Conselho Nacional de Desenvolvimento Científico e Tecnológico/Brazilian National Council of Scientific and Technological Development - grant 311868/ 2018-5), and CAPES (Coordenação de Aperfeiçoamento de Pessoal de Nivel Superior/Coordination for the Improvement of Higher Education Personnel - Finance code 001).

Conflict of interest: The authors confirm no conflict of interest.

\section{References}

1. Tang J, Hong YK, Inanoglu S, Liu F. Microwave pasteurization for ready-to-eat meals. Curr Opin Food Sci 2018;23:133-41.

2. Singh RP, Heldman DR. Introduction to food engineering, 4th ed. Cambridge: Academic Press; 2009.

3. Stoforos GN, Farkas BE, Simunovic J. Thermal mixing via acoustic vibration during continuous flow cooling of viscous food products. Food Bioprod Process 2016;100:551-9.

4. Aguiar HF, Gut JAW. Continuous HTST pasteurization of liquid foods with plate heat exchangers : mathematical modeling and experimental validation using a time - temperature integrator. J Food Eng 2014;123:78-86.

5. Levenspiel 0 . Chemical reaction engineering, 3rd ed. New York: John Wiley \& Sons; 1999.

6. Fogler HS. Elements of chemical reaction engineering, 5th ed. Prentice-Hall; 2016.

7. Gao Y, Muzzio FJ, lerapetritou MG. A review of the Residence Time Distribution (RTD) applications in solid unit operations. Powder Technol 2012;228:416-23.

8. Gutierrez CGCC, Dias EFTS, Gut JAW. Residence time distribution in holding tubes using generalized convection model and numerical convolution for non-ideal tracer detection. J Food Eng 2010;98:248-56.

9. Ruthven DM. The residence time distribution for ideal laminar flow in helical tube. Chem Eng Sci 1971;26:1113-21.

10. Sudarsan AP, Ugaz VM. Multivortex micromixing. Proc Natl Acad Sci U S A 2006;103:7228-33.

11. Kurt SK, Gelhausen MG, Kockmann N. Axial dispersion and heat transfer in a milli/microstructured coiled flow inverter for narrow residence time distribution at laminar flow. Chem Eng Technol 2015;38:1122-30.

12. Koutsky JA, Adler RJ. Minimisation of axial dispersion by use of secondary flow in helical tubes. Can J Chem Eng 1964;42: 239-46.

13. Saxena AK, Nigam KDP. Coiled configuration for flow inversion and its effect on residence time distribution. AIChE J 1984;30: 363-8.
14. Nauman EB. Residence time theory. Ind Eng Chem Res 2008;47: 3752-66.

15. Arellano M, Benkhelifa H, Alvarez G, Flick D. Experimental study and modelling of the residence time distribution in a scraped surface heat exchanger during sorbet freezing. J Food Eng 2013; 117:14-25.

16. Kechichian V, Crivellari GP, Gut JAW, Tadini CC. Modeling of continuous thermal processing of a non-Newtonian liquid food under diffusive laminar flow in a tubular system. Int J Heat Mass Tran 2012;55:5783-92.

17. Pegoraro PR, Marangoni M, Gut JAW. Residence time distribution models derived from non-ideal laminar velocity profiles in tubes. Chem Eng Technol 2012;35:1593-603.

18. Georget E, Sauvageat JL, Burbidge A, Mathys A. Residence time distributions in a modular micro reaction system. J Food Eng 2013;116:910-9.

19. Rennie TJ, Raghavan VGS. Numerical analysis of the lethality and processing uniformity in a double-pipe helical heat exchanger. Chem Eng Process Process Intensif 2010;49:672-9.

20. Martínez-Monteagudo SI, Yan B, Balasubramaniam VM. Engineering process characterization of high-pressure homogenization-from laboratory to industrial scale. Food Eng Rev 2017;9:143-69.

21. Sarang S, Heskitt B, Tulsiyan P, Sastry SK. Residence time distribution (RTD) of particulate foods in a continuous flow pilotscale ohmic heater. J Food Sci 2009;74. https://doi.org/10.1111/ j.1750-3841.2009.01248.x.

22. Ndoye FT, Erabit N, Alvarez G, Flick D. Influence of whey protein aggregation on the residence time distribution in a tubular heat exchanger and a helical holding tube during heat treatment process. J Food Eng 2012;112:158-67.

23. Siguemoto ÉS, dos S FE, Pires MN, Gut JAW. Modeling of timetemperature history and enzymatic inactivation of cloudy apple juice in continuous flow microwave assisted pasteurization. Food Bioprod Process 2018;111:45-53.

24. Guo X, Fan Y, Luo L. Residence time distribution on flow characterisations of multichannel systems: modelling and experimentation. Exp Therm Fluid Sci 2018;99: 407-19.

25. Essadki AH, Gourich B, Vial C, Delmas H. Residence time distribution measurements in an external-loop airlift reactor: study of the hydrodynamics of the liquid circulation induced by the hydrogen bubbles. Chem Eng Sci 2011;66: 3125-32.

26. Hutter C, Zenklusen A, Lang R, Rudolf von Rohr P. Axial dispersion in metal foams and streamwise-periodic porous media. Chem Eng Sci 2011;66:1132-41.

27. Abou Hweij K, Azizi F. Hydrodynamics and residence time distribution of liquid flow in tubular reactors equipped with screen-type static mixers. Chem Eng J 2015;279: 948-63.

28. Serres M, Schweich D, Vidal V, Philippe R. Liquid residence time distribution of multiphase horizontal flow in packed bed millichannel: spherical beads versus open cell solid foams. Chem Eng Sci 2018;190:149-63.

29. Gut JAW, Pinto JM, Gabas AL, Telis-romero J. Pasteurization of egg yolk in plate heat exchangers: thermophysical properties and process simulation. 2003 Annu Meet Sess 123. San Francisco: 2003:1-22 p. 
30. Mumbach GD, Lenz DLG, Wenzel BM. Investigation of hydrodynamic non-idealities in a pilot-scale pond bioreactor. J Water Process Eng 2018;23:97-108.

31. Levenspiel O, Bischoff KB. Patterns of flow in chemical process vessels. New York: Academic Press; 1964:95-198 p. Adv. Chem. Eng.

32. Danckwerts PV. Continuous flow systems. Distribution of residence times. Chem Eng Sci 1953;2:1-13.

33. Gouvêa MT, Park SW, Giudici R. Estimação de coeficientes de dispersão axial em leitos fixos. In: Proceedings of the XVIII Encontro sobre escoamento em meios porosos. Brazil; 1990;2:607-16.
34. Cretkovski CG, Reitsma S, Bolisetti T, Ting DSK. Heat transfer in a U-Bend pipe: Dean number versus Reynolds number. Sustain Energy Technol Assessments 2015;11:148-58.

35. Fillaudeau L, Le-Nguyen K, André C. Influence of flow regime and thermal power on residence time distribution in tubular Joule Effect Heaters. J Food Eng 2009;95:489-98.

36. Levenspiel O. The chemical reactor omnibook. Corvalis: OSU Book Stores; 1979.

37. Trivedi RN, Vasudeva K. RTD for diffusion free laminar flow in helical coils. Chem Eng Sci 1974;29:2291-5. 